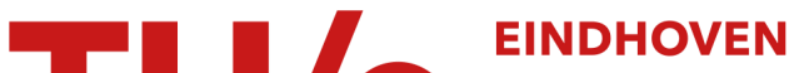 UNIVERSITY OF TECHNOLOGY
}

\section{Complex dielectric permittivity of engineering and 3D-printing polymers at Q-band}

\section{Citation for published version (APA):}

Reyes, N., Casado, F., Tapia, V., Jarufe, C., Finger, R., \& Bronfman, L. (2018). Complex dielectric permittivity of engineering and 3D-printing polymers at Q-band. Journal of Infrared, Millimeter, and Terahertz Waves, 39(11), 1140-1147. https://doi.org/10.1007/s10762-018-0528-9

DOI:

10.1007/s10762-018-0528-9

Document status and date:

Published: 01/11/2018

\section{Document Version:}

Accepted manuscript including changes made at the peer-review stage

\section{Please check the document version of this publication:}

- A submitted manuscript is the version of the article upon submission and before peer-review. There can be important differences between the submitted version and the official published version of record. People interested in the research are advised to contact the author for the final version of the publication, or visit the $\mathrm{DOI}$ to the publisher's website.

- The final author version and the galley proof are versions of the publication after peer review.

- The final published version features the final layout of the paper including the volume, issue and page numbers.

Link to publication

\section{General rights}

Copyright and moral rights for the publications made accessible in the public portal are retained by the authors and/or other copyright owners and it is a condition of accessing publications that users recognise and abide by the legal requirements associated with these rights.

- Users may download and print one copy of any publication from the public portal for the purpose of private study or research.

- You may not further distribute the material or use it for any profit-making activity or commercial gain

- You may freely distribute the URL identifying the publication in the public portal.

If the publication is distributed under the terms of Article $25 \mathrm{fa}$ of the Dutch Copyright Act, indicated by the "Taverne" license above, please follow below link for the End User Agreement:

www.tue.nl/taverne

Take down policy

If you believe that this document breaches copyright please contact us at:

openaccess@tue.nl

providing details and we will investigate your claim. 


\section{Complex Dielectric Permittivity of Engineering \& 3D-Printing Polymers at Q-Band.}

Nicolás Reyes ${ }^{\mathrm{a}} \cdot$ Francisco Casado $^{\mathrm{a}} \cdot$ Valeria Tapia $^{\mathrm{b}} \cdot$ Claudio Jarufe ${ }^{\mathrm{a}} \cdot$ Ricardo Finger $^{\mathrm{b}}$. Leonardo Bronfman ${ }^{\mathrm{b}}$.

This project received support from CONICYT through projects Fondecyt 11151022, Fondecyt 11140428, ALMA 31150012, and Center of Excellence in Astrophysics and Associated Technologies (PBF 06).

Nicolás Reyes

ORCID: 0000-0002-8522-4315

Universidad de Chile, Department of Electrical Engineering, Tupper 2007, Santiago, Chile;

Tel.: +56-229771119

E-mail: nireyes@uchile.cl

Francisco Casado

Universidad de Chile, Department of Electrical Engineering, Tupper 2007, Santiago, Chile;

Valeria Tapia

Universidad de Chile, Department of Astronomy, Camino el observatorio 1515, Santiago, Chile;

Claudio Jarufe

Universidad de Chile, Department of Electrical Engineering, Tupper 2007, Santiago, Chile;

Ricardo Finger

Universidad de Chile, Department of Astronomy, Camino el observatorio 1515, Santiago, Chile;

Leonardo Bronfman

Universidad de Chile, Department of Astronomy, Camino el observatorio 1515, Santiago, Chile; 
Abstract We report experimental values of the complex dielectric permittivity of a wide variety of engineering polymers. Measurements were done using the filling waveguide method at Q-band (30-50 GHz). This method has a high accuracy, providing excellent wide- bandwidth characterization. Measured samples include the most common engineering materials as polyamide, polyethylene, polytetrauoroethylene, polyoxymethylene, polylactic acid, phenol formaldehyde resin, polypropilene, polyvinyl chloride, acrylonitrile butadiene styrene, polyphenyle sulfide, and polyether ether ketone. Results are comprehensive and represent an important contribution to the technical literature which lacks of material measurements at these frequencies. Of particular interest are samples of 3D printed materials and high performance polymers that will probably and new and novel applications in the field of microwave components and antennas for the millimeter bands.

Key words Microwave characterization $\cdot$ Dielectric permittivity $\cdot$ Tangent loss

\section{Introduction}

Millimeter wave electronic have traditionally been associated with specific applications, as science research, defense, or space communications. Nowadays these technologies are growing into commercial applications for mass market. Current areas of development are the automotive radars at 77 to $90 \mathrm{GHz}$, the $60 \mathrm{GHz}$ low range communication networks , millimeter wave imaging systems, and development of $5 \mathrm{G}$ telecommunication systems based on MIMO in the millimeter wave bands. Here we refer the reader to good reviews

on this technologies as [1], [2], [3], [4]. A fundamental step for these high impact 
applications is the use of novel technologies, but also issues as weight, power consumption, fabrication costs, reproducibility, etc., are drivers as important as the final component performance. To achieve these goals the use of standard fabrication process is important. Synthetic organic polymers, or plastic materials, are one of the most versatile materials in the manufacturing industry. They are frequently used in the electronic industry due to their excellent insulation and mechanical properties, and they will certainly find applications in the mm-wave components and systems industry. In this paper we provide experimental data for the complex dielectric permittivity of a wide variety of such materials. We focus our measurements in the Q-band $(30-50 \mathrm{GHz}$ or 10 to $6 \mathrm{~mm}$ wavelength) as it is a representative frequency range of mm-wave regime. We used the filled waveguide method to characterize samples of the following materials: polyamide (PA6, PA66, PA6-C), polyethylene (PE, HDPE, treated HDPE), polytetrauoroethylene (PTFE), polyoxymethylene (POM), polylactic acid (PLA), acrylonitrile butadiene styrene (ABS), phenol formaldehyde resin, polypropilene (PP), polyvinyl chloride (PVC), polyphenyle sulfide (PPS) and polyether ether ketone (PEEK). Previous reports present data for some of these materials [5] [6], but the available data are generally measured at other frequency ranges. Specific materials as polyamides, polyethylenes and polytetrafluorethylene have already been studied and are well documented in the literature [7] [8] and [9], and represent a good comparison point for our set of measurements. Other materials as PLA and ABS are interesting due to their extensive use in the $3 \mathrm{D}$ Printing industry but the literature lacks of good measured data at this frequency ranges. Most of previous studies at higher frequencies have been performed using free-space techniques. 
At mm-wave regime this approach presents several problems as it requires large and thin samples to avoid diffraction in the borders and standing waves inside the material. The distance between the sample and the measuring antennas is also important as measurement precision can be affected by reflections between the sample and the antennas. Classical approaches using filled waveguides also use thin samples, as simple algorithms have the problem of increasing estimation uncertainty as the width of the sample gets too close to multiples of half the wavelength. This study overcomes this problem by preparing long samples of each material, where many standing wave maxima and minima are present along the frequency range, and considering not only single frequencies, but the whole interval to compute the permittivity.

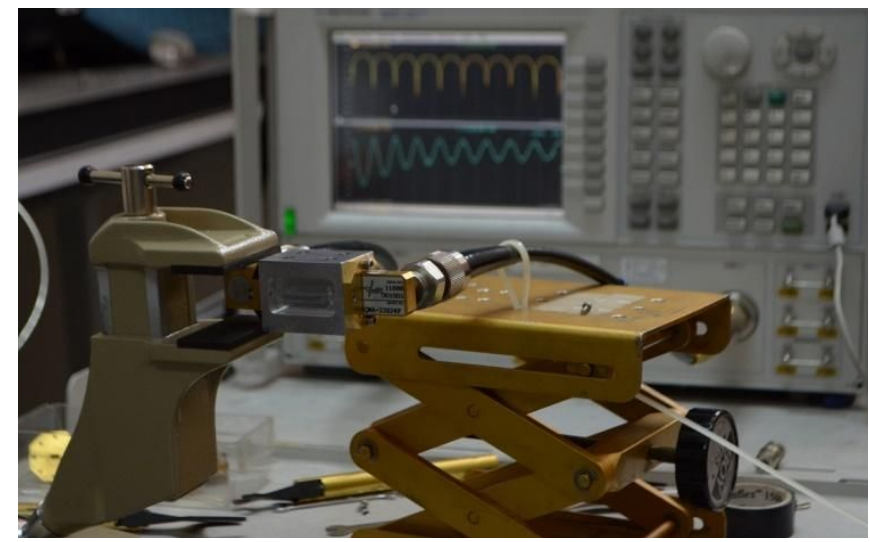

(a)

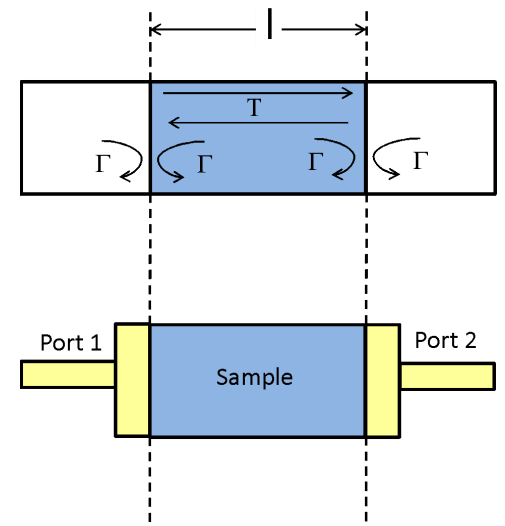

(b)

Fig 1 Experimental system for measurements of dielectric constant of materials. (a) Photography of the measurement system showing the vector network analyzer and the test fixture used for measurements. (b) Presents a conceptual scheme of the measurement system modeled as a partially filled waveguide with a sample of length $d$. The analyzer measures the scattering parameters S11 and S21. The reference plane is located at the interface between material and air filled waveguide.

\section{Experimental method}


The experimental set-up considers a rectangular waveguide completely filled with a sample of the material under test. Samples are machined in a high precision CNC to achieve a good surface quality and to avoid air gaps between the waveguide walls and the sample under test. The waveguide assembly is produced as a split block with the siege at the zero current plane. Plastic samples are inserted inside the waveguide assembly prior to each measurement. Despite using the same process different plastics show different surface qualities due to their inherent different mechanical properties, a final manual polishing was required to uniform the final surface quality of the samples. The scattering parameters of the filled waveguide are measured using a $50 \mathrm{GHz}$ Vector Network Analyzer (VNA) as shown in Figure 2(a). A couple of $2.4 \mathrm{~mm}$ coaxial to WR22 waveguide adapters are used between the VNA connector and the waveguide assembly. The effect of adapters and cables is removed by the standard 2-port SOLT calibration procedure. As a result the measured scattering parameters correspond to the reflection and transmission at the interfaces between our material and the air filled waveguide, as shown in Figure 2(b). At this frequency range it is important to have in mind that VNA cables can induce phase errors if they are twisted or moved after the calibration procedure. Our setup reduces this effects by having one of the ports mechanically fixed to the test bench and a system that minimizes bending during successive connection and disconnections of the samples.

\subsection{Permittivity Estimation}

The system can be modeled as a couple of air filled rectangular waveguides that interface with a central section of waveguide filled with the material under test, as represented in 
Figure 2(b). The measured S-parameters are related with the complex dielectric permittivity by equations (1) - (6). The effect of multiple reflections inside the sample in the measured scattering parameters is presented in Equations (1) and (2).

$$
\begin{aligned}
& S_{11}=S_{22}=\frac{\Gamma\left(1-\mathrm{T}^{2}\right)}{1-\Gamma^{2} \mathrm{~T}^{2}} \\
& S_{21}=S_{12}=\frac{\mathrm{T}\left(1-\Gamma^{2}\right)}{1-\Gamma^{2} \mathrm{~T}^{2}}
\end{aligned}
$$

, where $\Gamma$ represents the reflection coefficient at the interface between the filled waveguide and the air filled waveguide. $T$ represents the transmission coefficients between the two ends of the sample. Both coefficients are related to the waveguide propagation constants as presented in equations (3) and (4).

$$
\begin{aligned}
& \Gamma=\frac{\gamma_{0}-\gamma}{\gamma_{0}+\gamma} \\
& \mathrm{T}=e^{-\gamma l}
\end{aligned}
$$

Each waveguide is characterized by its own propagation constant, $\gamma$ for the filled waveguide, and $\gamma_{0}$ for the air filled waveguide.

$$
\begin{aligned}
& \gamma=\sqrt{\kappa_{c}^{2}-\epsilon_{r} \kappa_{0}^{2}} \\
& \gamma_{0}=\sqrt{\kappa_{c}^{2}-\epsilon_{0} \kappa_{0}^{2}}
\end{aligned}
$$

Where $\mathrm{k} 0$ is the wave number in free-space $\left(\kappa_{0}=\omega \sqrt{\epsilon_{0} \mu_{0}}\right)$, and kc represents the cut-off wave number of the TE01 mode, which for a rectangular waveguide becomes $\frac{\kappa_{c}=\pi}{a}$ with $a$ being the width of the waveguide. It is reasonable to assume a relative permeability of the sample equal to $1\left(\mu_{0}=1\right)$. Finally, $\epsilon_{r}=\epsilon_{r}^{\prime}+j \epsilon_{r}^{\prime \prime}$ is the complex relative permittivity 
of the material. We present here the complex part of the dielectric constant as the tangent loss, which is computed as (7),

$$
\tan \delta=\frac{\epsilon_{r}^{\prime \prime}}{\epsilon_{r}^{\prime}}
$$

Two of the most common methods to compute the complex permittivity are the Nicolson-Ross-Weir (NWR) [10] and the NIST Non-Iterative [11], which achieve good results when the length of the sample is not close to multiples of half the wavelength of interest. However, the computing power has increased to a point where more sophisticated error-minimization algorithms can be used to estimate the permittivity value. This is the method used in the paper, where the algorithms finds the best $\epsilon_{r}$ that minimizes the mean squared- error between the measured S-parameters and the model described by the equations (1)-(5). It is assumed that dielectric permittivity has no significant variation over the limited frequency range of this study, allowing the algorithm to estimate a global-average permittivity using all the available data, minimizing uncertainty. However, the analysis can be also performed over a specific frequency interval if required.

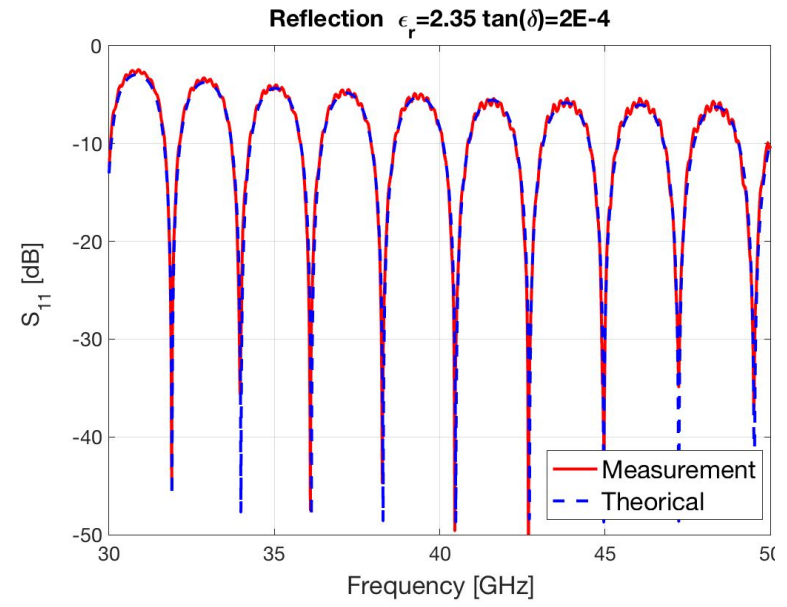

(a)

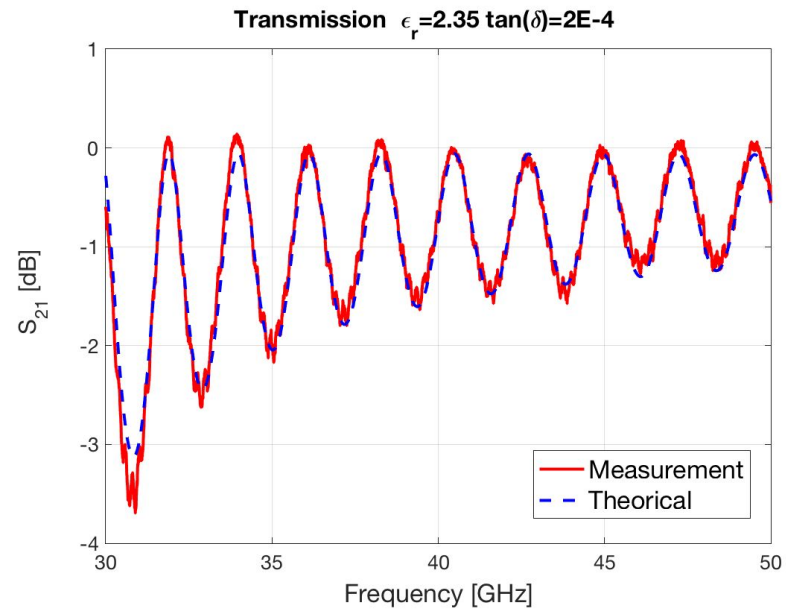

(b) 
Fig 2 Experimental and modeled response of the filled waveguide system. The vector analyzer measures the scattering parameters of the sample. (a) shows the reflected power across the frequency range and corresponds to the measured scattering parameter S11. (b) shows the transmitted power across the frequency range and corresponds to the measured parameter S21. Data are presented in logarithmic scale (dB).

Table 1 Summary of reported permittivity values for plastic materials. We also present for comparison previous published values. Relevant references are [6] [7] [8] and [9].

\begin{tabular}{|c|c|c|c|c|c|c|}
\hline \multirow{2}{*}{ Family } & \multirow{2}{*}{ ID } & \multicolumn{2}{|c|}{ Permittivity $\left(\epsilon_{r}\right)$} & \multicolumn{2}{|c|}{ Tangent loss $(\tan \delta)$} & \multirow{2}{*}{ Reference } \\
\hline & & Reported & Ref & Reported & Ref & \\
\hline PTFE & 1 & 2.03 & $1.75-2.10$ & $3.0 \mathrm{E}-4$ & $2.0-6.0 \mathrm{E}-4$ & [6] [7] [8] [9] \\
\hline Polyamide & $\begin{array}{l}1 \\
2 \\
3 \\
4\end{array}$ & $\begin{array}{l}3.06 \\
3.05 \\
3.06 \\
3.01\end{array}$ & 3.20 & $\begin{array}{l}1.1 \mathrm{E}-2 \\
1.0 \mathrm{E}-2 \\
1.2 \mathrm{E}-2 \\
1.0 \mathrm{E}-2\end{array}$ & $8.5 \mathrm{E}-3$ & [6] \\
\hline Polyethylene & $\begin{array}{l}1 \\
2 \\
3 \\
4 \\
5\end{array}$ & $\begin{array}{l}2.32 \\
2.32 \\
2.30 \\
2.36 \\
2.34\end{array}$ & $2.29-2.34$ & $\begin{array}{l}6.0 \mathrm{E}-4 \\
2.0 \mathrm{E}-4 \\
9.0 \mathrm{E}-4 \\
11.0 \mathrm{E} .4 \\
2.0 \mathrm{E}-4\end{array}$ & $2.0-5.0 \mathrm{E}-4$ & {$[6][7]$} \\
\hline Polylactic acid & $\begin{array}{l}1 \\
2 \\
3\end{array}$ & $\begin{array}{l}2.57 \\
2.72 \\
2.71\end{array}$ & & $\begin{array}{l}9.5 \mathrm{E}-3 \\
10.0 \mathrm{E}-3 \\
10.0 \mathrm{E}-3\end{array}$ & & \\
\hline $\mathrm{ABS}$ & 1 & 2.40 & & $5.5 \mathrm{E}-3$ & & \\
\hline POM & $\begin{array}{l}1 \\
2\end{array}$ & $\begin{array}{l}2.79 \\
2.97\end{array}$ & & $\begin{array}{l}1.8 \mathrm{E}-2 \\
0.7 \mathrm{E}-2\end{array}$ & & \\
\hline
\end{tabular}




\begin{tabular}{|l|c|c|c|c|c|c|}
\hline Polypropylene & 1 & 2.27 & $2.17-2.25$ & $7.0 \mathrm{E}-4$ & $1.0-7.5 \mathrm{E}-4$ & [6] [7] [9] \\
\hline PVC & 1 & 2.83 & & $7.6 \mathrm{E}-3$ & & \\
\hline Phenol resin & 1 & 3.58 & & $6.6 \mathrm{E}-2$ & & \\
& 2 & 3.73 & & $5.7 \mathrm{E}-2$ & & \\
\hline PEEK & 1 & 3.12 & & $4.4 \mathrm{E}-3$ & & \\
\hline PPS & 1 & 3.09 & & $4.1 \mathrm{E}-3$ & & \\
\hline
\end{tabular}

\section{Results}

Table 1 shows the obtained results for our samples. For each material family we tested several samples from different providers, and with different features as color, production system or commercial name. For each sample several measurements were done. The measured complex relative permittivity is expressed as the real part $\epsilon_{r}^{\prime}$ of the dielectric constant and the tangent loss of the material. In the same table we present values previously reported in the literature to easily compare our results with previous reported or non-existing data. The first presented material is PTFE or teflon, a widely used material for microwave components, that has $\epsilon_{r}=2.0$ and an relatively small tangent loss of 3.0 E-4. Our measurements are coincident with previous data and this measurement was used as a comparative point to other reports in the literature. Polyamides are widely used as synthetic fibers in the textile industry. They are also used as engineering plastic. The most common material in this family is nylon. We measured four samples from different providers of nylon. Samples 1 and 2 correspond to PA6, sample 3 is a PA66, and sample 4 is a PA6 with addition of molybdenum disulfide. They have similar dielectric constant values around $\epsilon_{r}=3.1$ and a high tangent loss of approximately 1.0 E-2. Different 
samples of polyethylene have little differences on their absolute permittivity values, but relatively large variations in the tangent loss values. We found that little differences, as the presence of colorants in otherwise identical materials have an appreciable impact on the value of tangent losses (samples 1 and 2). No large variation is appreciated along with different molecular weights of the materials (samples 3 and 4). The obtained values are similar to previously reported values. Polylactic acid is widely used in additive manufacturing processes. We measure three samples produced in 3D printing machines from different providers. They exhibit a tangent loss of the order of 1.0E-2, and a $\epsilon_{r}$ in the range of 2.6 to 2.8. The acrylonitrile butadiene styrene or ABS is a strong and resistant plastic that is widely used in the electronic industry. The sample was produced using $3 \mathrm{D}$ printing technology. The measured dielectric constant is 2.4 with a tangent loss of $5.5 \mathrm{E}-3$, almost half of the losses measured for PLA. POM is a thermoplastic material with excellent mechanical properties. It is used for parts that require high dimensional stability, resistance, and rigidity. Our measurements of two samples from different providers show a tangent loss in the range of $7.0 \mathrm{E}-3$ to $1.8 \mathrm{E}-2$ and a dielectric constant between 2.8 and 3.0. We measured just one sample of polypropylene, a well-known low loss material, used in radomes and infrared filters along the mm-wave band. 


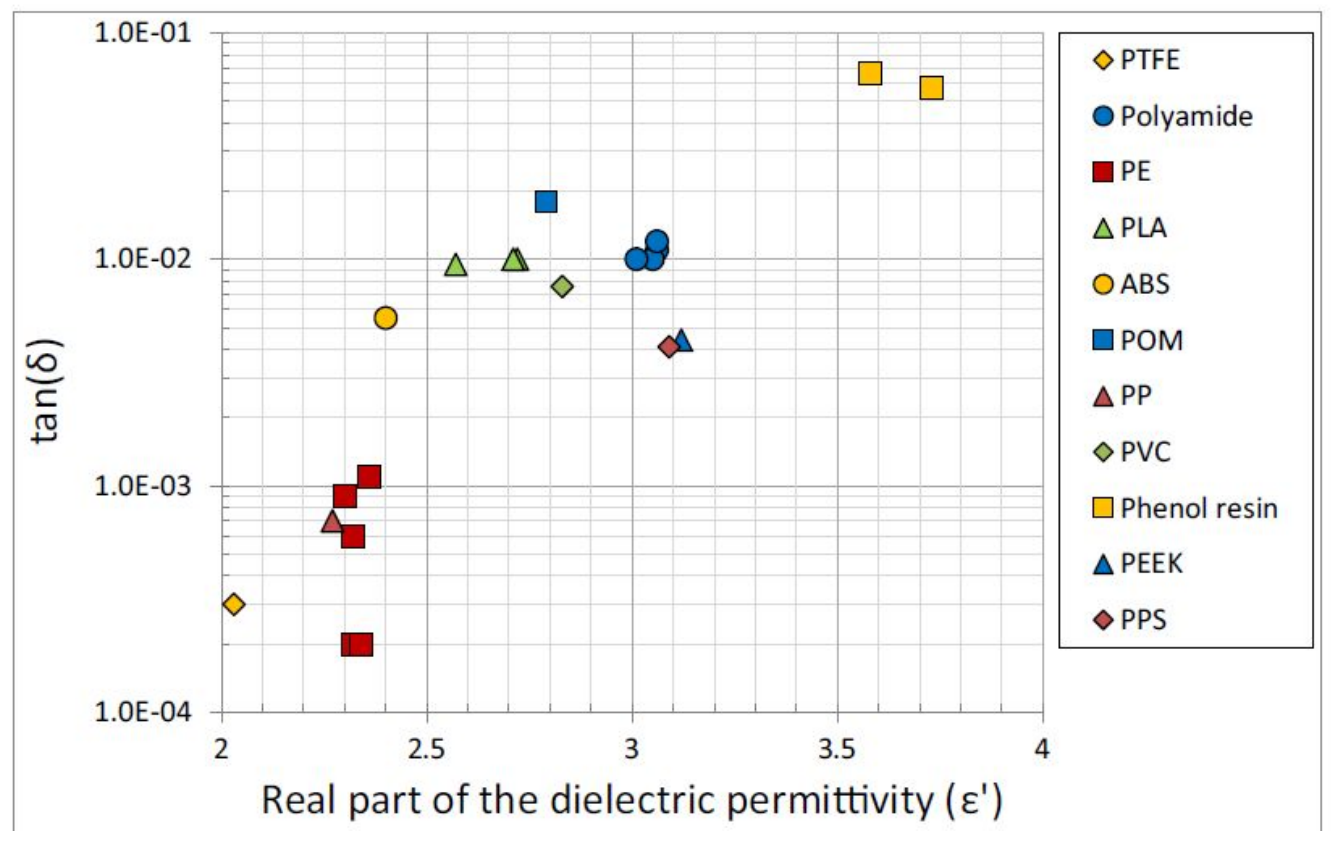

Fig 3 Summary of results showing the measured dielectric permittivity and tangent losses of different materials.

Our measurement indicates a tangent loss in the range of $7.0 \mathrm{E}-4$ and $\epsilon_{r}=2.3$. PVC is one of the most common polymers used in the industry for many applications. The measured permittivity is 2.8 and the tangent loss is in the order of 7.5 E-3. Phenol resin compound presents the highest permittivity of all the tested materials but also the higher tangent loss. The difference between different samples is noticeable. Polyether ether ketone or PEEK is an advanced engineering plastic material. Its robustness makes it suitable for demanding applications; it is also considered an advanced biomaterial for implants. Other advanced plastic material is the Polyphenylene sulfide or PPS. This material is used in chemical aggressive ambient as no acid or alkaline compound attack it. The material is interesting as precursor for electrical conducting plastic materials. Both PEEK and PPS present 
similar results. They have a relatively high dielectric constant of 3.1 and a low tangent loss of the order of $4.0 \mathrm{E}-3$.

\section{Conclusion}

We have presented a comprehensive set of data for complex dielectric permeability of different thermoplastic compounds. Measurements were performed in the mm-wave range providing valuable information for component designers working in the millimeter wave bands. Figure 3 presents a complete overview of the performed material characterizations.

\section{References}

[1] Hasch, Jürgen, et al., "Millimeter-Wave Technology for Automotive Radar Sensors in the $77 \mathrm{GHz}$ Frequency Band", IEEE Microwave Theory and Techniques, Vol. 60, Issue 3, pp 845-860, Mar (2012)

[2] Daniels, R. C., and R. W. Heath Jr. " $60 \mathrm{GHz}$ wireless communications: emerging requirements and design recommendations", IEEE Vehicular Technology Magazine, Vol 2, Issue 3, pp 41-50, Sept (2007).

[3] Appleby, R., et al. "Millimeter-Wave and Submillimeter-Wave Imaging for Security and Surveillance", Proceedings of the IEEE, Vol. 95, pp 1683-1690, Aug (2007).

[4] Gupta, A., and R. K. Jha. "A Survey of 5G Network: Architecture and Emerging Technologies", IEEE Access, Vol 3, pp 1206-1232, July (2015).

[5] Bur, Anthony J. "Dielectric properties of polymers at microwave frequencies: a review", Polymer, Vol 26, Issue 7,pp 963-977, July (1985). 
[6] Lamb, James W. "Miscellaneous data on materials for millimetre and submillimetre optics", International Journal of Infrared Millimeter Waves, Vol 17, Issue 12, pp 1997-2034, Dec (1996.).

[7] Krupka, Jerzy. "Measurement of the Complex Permittivity of Low Loss Polymers at Frequency Range From $5 \mathrm{GHz}$ to $50 \mathrm{GHz}$ " IEEE Microwave and Wireless components letters, Vol 26, No 6, pp 464-466, June (2016)

[8] Rahman, Nahid, et al. "Millimeter Wave Complex Permittivity Measurements of High Dielectric Strength Thermoplastics." IEEE International Instrumentation and Measurement Technology Conference. Victoria, Canada, May 12- 15, (2008)

[9] Afsar, Mohammed et al. "Complex Dielectric Measurements of Materials at Q- Band, V- Band and W- Band Frequencies with High Power Sources." IEEE International Instrumentation and Measurement Technology Conference. Ottawa, Ontario, Canada. May 17-19, (2005)

[10] Nicolson, A. M., and G. F. Ross. "Measurement of the Intrinsic Properties of Materials by Time-Domain Techniques", IEEE transactions on instrumentation and measurement, Vol 19, No 4, pp 377-382, Nov (1970).

[11] Baker-Jarvis, et al. 'Improved Technique for Determining Complex Permittivity with the Transmission/Reflection Method", IEEE Transactions on Microwave Theory and Techniques, Vol 38, No 8, pp 1096-1103, Aug (1990). 